Check for updates

\section{The BMJ}

Cite this as: BMJ 2021;373:n1576 http://dx.doi.org/10.1136/bmi.n1576 Published: 17 June 2021

\section{Covid-19: Vaccination to become mandatory for care home staff and could extend to NHS}

Clare Dyer

Staff in care homes in England will be required to be vaccinated against covid-19 and the government is to consult on whether to extend the requirement to those working in the NHS. ${ }^{1}$

From October, if the legislation is approved by parliament, staff and volunteers working in care homes registered by the Care Quality Commission (CQC) will have to have two doses of a covid-19 vaccine unless they have a medical exemption.

The requirement will apply to full or part time agency staff, workers employed directly by the care home or provider, and volunteers working with residents. Those coming into a care home to do other work, such as healthcare workers and CQC inspectors, will also have to follow the new rules.

The government has announced that it will launch a new consultation on making it compulsory for NHS staff to be vaccinated against covid-19 and flu.

Chaand Nagpaul, chair of BMA council, said, "While some healthcare workers already need to be immunised or show they are not infectious with other diseases to work in certain areas, any specific proposal for the compulsory vaccination of healthcare staff against covid-19 would raise new ethical and legal implications." He added, "Compulsion is a blunt instrument to tackle a complex matter. Recent research has highlighted that pressurising health and social care workers can have damaging effects, leading to an erosion of trust, worsening concerns about the vaccine, and hardened stances on declining vaccination."

Nagpaul said efforts should be focused on targeted engagement and any policy must avoid discrimination, given that vaccine uptake is lower in some ethnic minority groups. "Crucially, doctors who have faced such a gruelling year, and may have given decades of their lives to the NHS, must not now or in future face losing their jobs for declining a vaccine," he said.

Only $65 \%$ of care homes for older people in England meet the minimum level of staff uptake for one dose of the vaccine which the Scientific Advisory Group for Emergencies advises provides a minimum level of protection against covid-19 outbreaks. The percentage falls to $44 \%$ of care homes in London.

David Lock QC, a specialist in healthcare law, said a mandatory vaccination requirement would undoubtedly be an interference with the individual's rights under article 8 of the European Convention on Human Rights, the right to privacy, but the question was whether the interference was justified. If so, employers could lawfully require vaccination.

"The answer is probably yes, it is justified, provided anybody who has a justifiable reason not to have the vaccine is able to work without having had the vaccine," he told The BMJ. "Those who on a whim or for an objectively unjustifiable reason exercise their right not to have the vaccine don't necessarily have the right to continue with patient facing employment."

1 Wise J. Covid-19: Is the UK heading towards mandatory vaccination of healthcare workers?BM/2021;373:n1056. doi: 10.1136/bmj.n1056 pmid: 33883193

This article is made freely available for use in accordance with BMJ's website terms and conditions for the duration of the covid-19 pandemic or until otherwise determined by BMJ. You may use, download and print the article for any lawful, non-commercial purpose (including text and data mining) provided that all copyright notices and trade marks are retained. 